\section{In tern ationa l \\ Journal of}

Medical

and Surgical Sciences

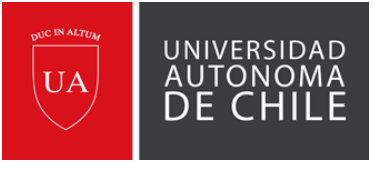

\title{
Disc stability after condylar discopexy with open surgery technique. A case report.
}

\author{
Angélica Valenzuela ${ }^{1} \&$ Jorge Beltrán. ${ }^{1,2}$
}

\section{ABSTRACT}

Of the temporomandibular joint (TMJ) pathologies, temporomandibular disorders (TMD) of disc displacement present several clinical signs and symptoms, the main ones being joint pain measured with the visual analogue scale (VAS) reporting on average VAS $>6$, and functional incapacity measured in $\mathrm{mm}$ of mouth opening, reporting on average $<30 \mathrm{~mm}$ in cases of TMD. The present case corresponds to a patient with limitation of mouth opening $<15 \mathrm{~mm}$, joint pain VAS= 8 , and functional limitation. The subject's condition was diagnosed clinically and by magnetic resonance imaging (MRI). The patient presented a Wilkes VI lateral dislocation of the left condyle disc without reduction, treated with open surgery discopexy, with disc fixation by monocryl suture and retrodiscal thermocoagulation. The patient showed a significant improvement in the removal of pain and in joint function. In clinical checkups at 1 month, 3 months, 6 months and 1 year, the patient showed decrease of pain levels, from VAS $=8$ to VAS $=0$, and mouth opening of $<15 \mathrm{~mm}$ to $36 \mathrm{~mm}$ in the last checkup. Clinical and imaging evaluation at 4 years shows disc stability, with maximum mouth opening of $36 \mathrm{~mm}$, with no disc displacement and clinically asymptomatic VAS $=0$. In this case, discopexy with open surgery achieved improvements in functional capacity and removal of pain at short term. Long-term stability was associated with anatomical functions without alteration and without relapse of the symptomatology.

Keywords: temporomandibular joint, temporomandibular disorder, discopexy, open surgery.

\section{INTRODUCTION}

Disc displacements with or without reduction are internal disorders of the temporomandibular joint (TMJ) and a frequent cause of consultation. They present characteristic clinical signs and symptoms such as joint pain (usually VAS> 6), together with functional incapacity and maximum oral opening ranges of less than $30 \mathrm{~mm}$ (Tatli et al, 2017). The etiology of temporomandibular disorders (TMDs) continues to be studied and it is associated with several factors, such as: trauma, emotional stress, malocclusion and parafunctional habits such as bruxism (Madani \& Mirmortazavi, 2011).

The most commonly used classification of internal joint disorders was proposed by Wilkes in 1989. This classification is associated with the severity of the disorder and organized in five stages according to clinical, radiological and intraoperative findings. Stage I consists of disc displacement with early reduction, stage II disc displacement with late reduction, stage III disc displacement without acute or subacute reduction, stage IV chronic disc displacement without reduction, and stage V includes stage IV plus osteoarthrosis (Wilkes, 1989).

Of all TMDs, disc displacement without reduction is one of the worse clinical conditions, since the articular disc dislocates and does not return to its normal position in the mandibular movement (Tatli et al, 2017). This generates a closed block that increases the risk of degenerative changes in the joint (Martín-Granizo \& Millón-Cruz, 2016). Displacement of the disc is usually accompanied by a loss of structural integrity of the posterior medial and lateral disc ligaments due their rupture, tearing, herniation, stretching or degeneration (Mehra \& Wolford, 2001). 
Accurate diagnosis and treatment of TMD requires evaluation by imaging. Magnetic resonance imaging (MRI) provides the diagnostic accuracy required to evaluate joint disc position and joint morphology (Wilkes, 1989). There are two therapeutic options: conservative treatments (manual therapy, pharmacological treatment, modification of habits, physiotherapy and therapy with splints); and surgical treatments (arthrocentesis, arthroscopy and open surgeries) (Tatli et al, 2017). Surgical condylar treatments require complementation with joint physiotherapy to avoid hypomobility and ankylosis, including opening and closing exercises of the TMJ (Capan et al., 2017).

Discopexy is a stabilization treatment of the articular disc in a functional position, using an open or minimally invasive technique, such as arthroscopy. The open surgical technique consists of articular exposure, allowing disc repositioning and fixation to avoid displacements in movements of the joint (MCCain et al., 2015).

The aim of this article is to report the successful follow-up at 4 years of a case of disc displacement without reduction treated with discopexy using an open surgical technique.

\section{CASE REPORT}

Thirty-two year old female patient, who consulted for pain in the left TMJ, VAS=8, accompanied with functional incapacity, with an opening limitation of $<15 \mathrm{~mm}$ and without joint noises. The patient's medical history showed dyslipidemia treated with atorvastatin $20 \mathrm{mg} /$ day.

Physical examination revealed functional alteration in joint dynamics and repetitive closed block with preserved occlusal support. Within the patient's clinical history, a previous treatment with myorelaxants, NSAIDs and subsequent relaxation program supervised by a specialist in temporomandibular dysfunction were found. The patient was referred by a treating specialist with a MRI diagnosis of bilateral TMD to the Maxillofacial Surgery Unit at Hospital Clinico in the city of Curanilahue, Chile. MRI showed the right TMJ without alterations of the disc position or anatomical changes in articular surfaces. The left TMJ had the articular disc displaced towards medial, morphological alterations of erosive character in cortical section corresponding to the superior pole of the mandibular condyle, increase of intensity in supra and infradiscal compartments. In the dynamic study, the articular disc was anteriorly displaced with respect to the mandibular condyle. At $5 \mathrm{~mm}$ opening, the disc remains anteriorly displaced with respect to the mandibular condyle with short asymmetrical condylar path and bilateral condylar hypomobility (Fig. 1).

MRI and clinical evaluation suggested the diagnosis of disc displacement without reduction, with closed joint blockage, and Wilkes's stage IV (Fig. 2). Conventional non-surgical techniques, such as pharmacological treatment with myorelaxants and NSAIDs plus orthopedic treatment (relaxation plane/therapy), were some of the treatment options the patient underwent without obtaining favorable results.

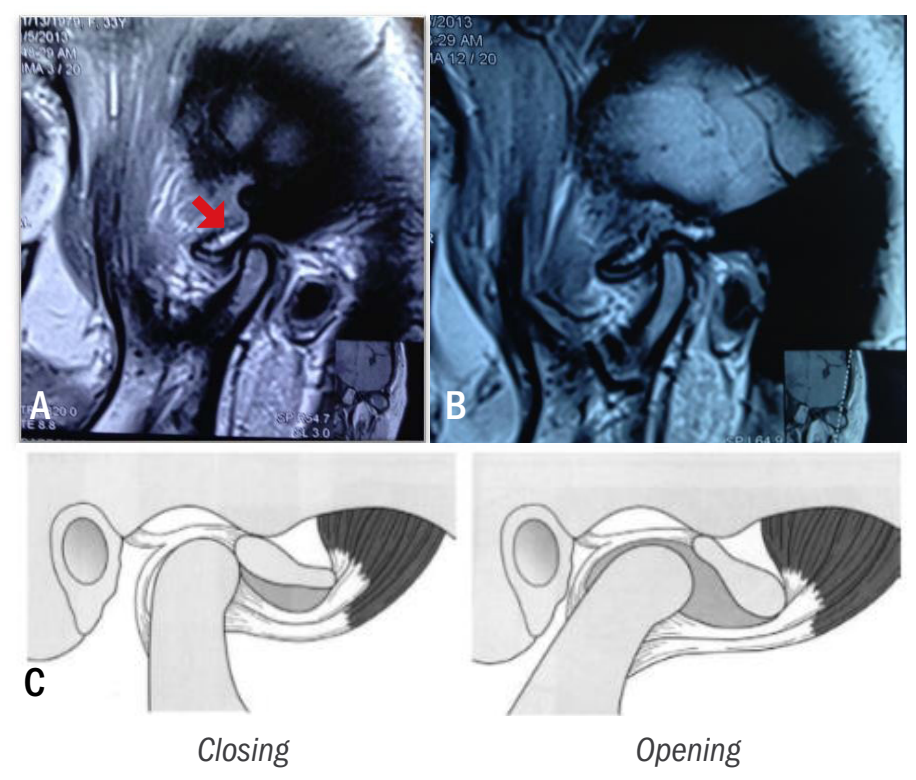

Figure 1: Figure $1 \mathrm{~A}$. Preoperative MRI of the left TMJ with disc displacement without reduction (discocondylar dislocation). $B$. MRI of healthy right TMJ. C. Joint dislocation scheme without reduction.

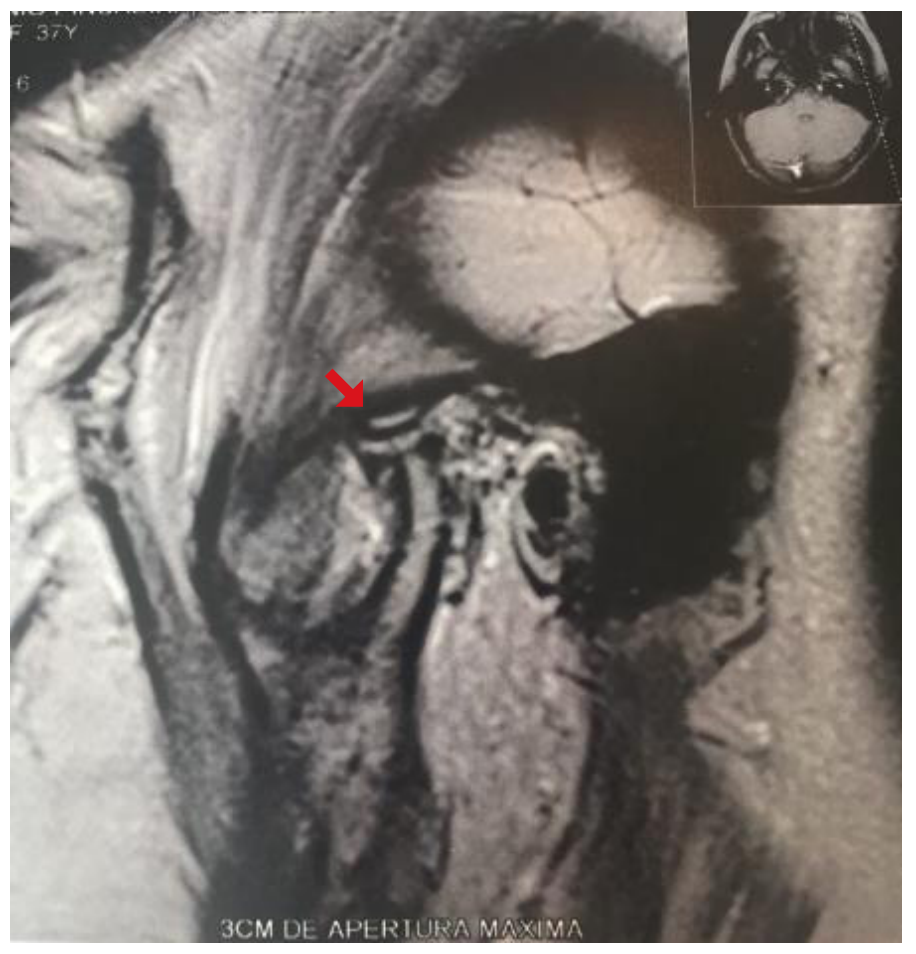

Figure 2: MRI at 4-year checkup. Left TMJ with disc joint repositioned with early reduction and disc stability, without morphological alterations. 
Among the surgical options, arthroscopic discopexy and discopexy with open surgery technique were considered. Arthroscopic treatment requires experience and surgical training (Elledge et al, 2017), consequently, it was decided to perform a disc repositioning surgery (discopexy) with open surgery technique.

The patient underwent surgery under general anesthesia, using endaural approach with extension in "golf club", arthrotomy was performed exposing temporomandibular joint and pexia at the posterior retrodiscal tissue, by means of monocryl suture with retrodiscal thermo-coagulation to generate retrodiscal tissue contraction and articular disc retraction. Lateral capsule fixation and flap repositioning were performed.

After a day of hospitalization, the following postoperative indications and drugs were prescribed: soft diet for 3 weeks, Prednisone $20 \mathrm{mg}$ every 12 hours for 3 days, Ketoprofen 100 mg every 12 hours for 5 days, Cyclobenzaprine 5 mg daily for 10 days and isometric contraction exercises.

Clinical checkups were performed at 1 week, 3 months, 6 months, one year, achieving maximum mouth opening at 3 months, results that remain until the date of this report (Table 1).

Table 1: Comparison of the measurements obtained at maximum openong in preoperative evaluation, and the postoperative checkups.

\begin{tabular}{|c|c|c|c|c|c|c|}
\hline Checkup & Preoperative & $\begin{array}{c}1 \\
\text { month }\end{array}$ & $\begin{array}{c}2 \\
\text { month }\end{array}$ & $\begin{array}{c}3 \\
\text { month }\end{array}$ & $\begin{array}{c}4 \\
\text { month }\end{array}$ & $\begin{array}{c}5 \\
\text { month }\end{array}$ \\
\hline $\begin{array}{c}\text { Maximum } \\
\text { opening }\end{array}$ & $<15 \mathrm{~mm}$ & $\mathbf{3 2 \mathrm { mm }}$ & $\mathbf{3 6 \mathrm { mm }}$ & $\mathbf{3 6 \mathrm { mm }}$ & $\mathbf{3 6 \mathrm { mm }}$ & $\mathbf{3 6 \mathrm { mm }}$ \\
\hline
\end{tabular}

A new MRI evaluation was performed 4 years after surgery to measure disc stability. It showed that the right TMJ had no morphological alterations and no signal intensity in meniscus and temporal and mandibular joint surfaces. Left TMJ (surgicaIly treated) had anterior meniscal displacement secondary to disc-condylar dislocation with reduction in early stages, with no anatomical changes and no signal intensity in meniscus and temporal and mandibular joint surface. A short condylar path, asymmetrical in appearance and normal condylar mobility were observed.

The patient was thankful and grateful for the removal of pain and for having recovered her joint function.

\section{DISCUSSION}

TMDs cause pain in the temporomandibular region and masticatory muscles, crepitation or articular click, blockage, alteration of mandibular movement and displacement of the articular disc (Yang et al, 2017).

Ninety per cent of the internal TMJ disorders respond to conservative therapy, but $10 \%$ are refractory to non-surgical treatments and require surgical management. Disc repositioning surgery can mitigate degeneration caused by internal alterations by eliminating mechanical interference and facilitating coordinated movement of the joints (Rajkumar et al., 2016).

Regarding the method of diagnosis, Zhang describes the advantages of MRI over other imaging tests, highlighting its superiority over arthrography. MRI has a high definition in soft tissue, showing in detail the structure of organs and tissues. It is a nonradioactive technique, being less invasive or harmful compared to other tests that require radiation. One of the main advantages of MRI is that it has higher image and information parameters, and it is able to handle different densities such as T1, T2 and proton density, ideal to study TMJ, due to its bone and soft tissue components (Zhang et al., 2010).

Among the objectives of disc repositioning surgery are the removal of pain and mechanical interference, and also stopping the progression of disc degeneration and osteoarthritis. The clinical results of disc repositioning surgery have been variable and often unpredictable, with failures related to the long-term stability, requiring the use of a method for the stabilization of the disc. Traditionally, disc replacement technique involves the suturing (plication) of the inflamed and degenerate ligament, which can result in instability of disc repositioning. There have been improvements in the technique of disc fixation, using metal bone anchors with the main disadvantage of device loosening and alteration of image in MRI due to the presence of artifacts. Replacement techniques are preferred with resorbable materials, such as the monocryl suture technique used in this case or resorbable fixation devices (Restrepo, 2014).

It has been reported in the literature that the use of absorbable sutures in the lateral soft tissue of the condyle may lead to gradual relaxation or prolapse of soft tissues, causing recurrent dislocation of the disc, more frequently in cases of long-term TMJ degenerative disorders (Cascone et al., 2008). However, the long-term postoperative stability reported in this case proves that this may be a safe technique of direct fixation with functional stability maintained over time.

Regarding long-term postoperative success rate or stability, there is much controversy with a higher success rate in surgical treatments (arthroscopy) related to Wilkes stages II and III, with success rates of $82 \%$ and $89 \%$, respectively (MCCain et al., 2015). This is why in IV or V stages, open surgery should be used, since severe deformation is severe in those cases (Zhang et al., 2010). 
McCarty and then Dolwick described success rates of approximately $94 \%$ in cases treated with open discopexy, but in both studies the reported outcomes were for all phases of internal TMJ disorders. They did not specify the success rate in each of the different Wilkes' classifications, resulting in very different clinical characteristics of the stages (McCain et al., 2015).

The treatment of TMJ dysfunction is widely debated in the literature, with good results reported for both arthroscopic techniques and open surgery; however, relapses are also reported, which determine the stability of the therapeutic resolution over time (Spallaccia et al., 2013).

\section{CONCLUSION}

In this case, discopexy with open technique achieved improvements in functional capacity and short-term pain removal. Long-term stability was associated with anatomical functions without alterations and without relapse of the symptomatology.

\section{REFERENCES}

Capan N, Esmaeilzadeh S, Karan A, Diracoglu D, Emekli U, Yildiz A, Baskent A, Aksoy C. Effect of an early supervised rehabilitation programme compared with home-based exercise after temporomandibular joint condylar discopexy: a randomized controlled trial, Int J Oral Maxillofac Surg. 2017;46(3):314-321.

Cascone P, Ungari C, Paparo F, Marianetti TM, Ramieri V, Fatone M. A new surgical approach for the treatment of chronic recurrent temporomandibular joint dislocation. J Craniofac Surg. 2008;19(2):510-512.

Elledge R, Green J, Attard A. Training in surgery of the temporomandibuIar joint: the UK trainers' perspective. Br J Oral Maxillofac Surg. 2017;55(1):6166.

Madani AS, Mirmortazavi A. Comparison of three treatment options for painful temporomandibular joint clicking. J Oral Sci. 2011; 53(3): 349-354.

Martín-Granizo R, Millón-Cruz A. Discopexy using resorbable pins in temporomandibular joint arthroscopy: Clinical and magnetic resonance imaging medium-term results. J Craniomaxillofac Surg. 2016;44(4):479-86.

McCain JP, Hossameldin RH, Srouji S, Maher A. Arthroscopic discopexy is effective in managing temporomandibular joint internal derangement in WiIkes' stage II and III patients. J Oral Maxillofac Surg. 2015;73(3):391-401.

Mehra P, Wolford LM. The Mitek mini anchor for TMJ disc repositioning: surgical technique and results. Int J Oral Maxillofac Surg. 2001; 30(6): 497-503.

Rajkumar K, Mukhopadhyay P, Sinha R. Temporomandibular Joint Disc Repositioning Using

an Orthopedic Suture Anchor: A Modified Disc Anchoring Technique, J Maxillofac Oral Surg. 2016;15(3):404-407.

Restrepo A. "Plicatura del disco articular (discopexia) con mini anclajes absorbibles en estadios avanzados de disfunción de la articulación temporomandibular según la clasificación de wilkes, en el hospital universitario de la samaritana, Bogotá, Colombia. Enero del 2011 a Junio de 2013". [Thesis]. Bogotá, Colombia: Universidad Nacional de Colombia; 2014.

Spallaccia F, Rivaroli A, Basile E, Cascone P. Disk Repositioning Surgery of the Temporomandibular Joint With Bioabsorbable Anchor. J Craniofac Surg. 2013;24(5): 1792-1795.

Tatli U, Benlidayi ME, Ekren 0, Salimov F. Comparison of the effective- ness of three different treatment methods for temporomandibular joint disc displacement without reduction. Int J Oral Maxillofac Surg. 2017;46(5):603609.

Wilkes $\mathrm{CH}$. Internal derangements of the temporomandibular joint. Pathological variations. Arch Otolaryngol Head Neck Surg. 1989; 115(4):469477.

Yang Z, Wang M, Ma Y, Lai Q, Tong D, Zhang F, Dong L. MRI evaluation for anterior disc displacement of the temporomandibular joint. Med Sci Monit. 2017; 23: 712-718.

Zhang SY, Liu XM, Yang C, Cai XY, Chen MJ, Haddad MS, Yun B, Chen ZZ. New arthroscopic disc repositioning and suturing technique for treating internal derangement of the temporomandibular joint: part II--magnetic resonance imaging evaluation. J Oral Maxillofac Surg. 2010; 68(8):1813-7. 